\title{
Contemporary assessment of laryngotracheal trauma
}

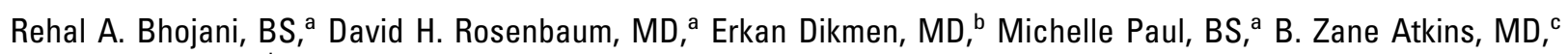
David Zonies, MD, ${ }^{d}$ Aaron S. Estrera, MD, ${ }^{a}$ Michael A. Wait, MD, ${ }^{a}$ Dan M. Meyer, MD, ${ }^{a}$ Michael E. Jessen, MD, and J. Michael DiMaio, MD

From the Department of Cardiovascular and Thoracic Surgery, ${ }^{\text {a }}$ University of Texas Southwestern Medical Center, Dallas, Tex; the Department of Thoracic Surgery, ${ }^{\text {b }}$ Kirikkale University, Kirikkale, Turkey; the Department of Cardiothoracic Surgery, ${ }^{\mathrm{C}}$ Duke University Medical Center, Durham, $\mathrm{NC}$; and the Department of Surgery, ${ }^{\mathrm{d}}$ Wilford Hall Medical Center, San Antonio, Tex.

Supported in part by the Donald W. Reynolds Cardiovascular Research Center. Supported in part by National Institutes of Health (5T32GM08593) Training Program in Burns, Trauma, and Critical Care.

Received for publication Oct 15, 2004; revisions received Dec 3, 2004; accepted for publication Dec 17, 2004.

Address for reprints: J. Michael DiMaio, MD, 5323 Harry Hines Blvd, Dallas, TX 75390-8879 (E-mail: michael.dimaio@ utsouthwestern.edu).

J Thorac Cardiovasc Surg 2005;130:426-32 $0022-5223 / \$ 30.00$

Copyright (C) 2005 by The American Association for Thoracic Surgery

doi:10.1016/j.jtcvs.2004.12.020
Objectives: Laryngotracheal trauma is a rare and potentially deadly spectrum of injuries. We sought to characterize the contemporary mechanisms, diagnostic modalities, and outcomes common in laryngotracheal trauma today.

Methods: We performed a retrospective analysis of all laryngotracheal trauma cases at 2 major metropolitan hospitals between 1996 and 2004, detailing mechanisms, associated injuries, diagnostic modalities, and outcomes of laryngotracheal trauma.

Results: We identified 71 patients with a mean age of $32.8 \pm 13.3$ years (range, 15-71 years). In our series penetrating trauma was the cause in $73.2 \%$ of patients; however, blunt trauma had a significantly higher mortality $(63.2 \%$ vs $13.5 \%$, respectively; $P<.0001)$. Blunt mechanisms involved older patients $(38.5 \pm 15.2$ years vs $30.1 \pm 11.9$ years, $P=.017$ ), and these patients were more likely to require emergency airways than those with penetrating trauma ( $78.9 \%$ vs $46.2 \%, P=.017$ ). The requirement of an emergency airway was an independent predictor of mortality $(P=.0066)$.

Conclusion: Laryngotracheal trauma is a deadly spectrum of injuries with a mortality of $26.8 \%$. Blunt mechanisms are decreasing in frequency. This might reflect improvements in automobile safety. Additionally, violent crime is on the increase, producing penetrating injuries with increasing frequency. The most fundamental intervention for patients with laryngotracheal injury is airway control. Either routine intubation or a tracheostomy can secure the airway. Blunt trauma and the requirement of an emergency airway are independent predictors of mortality. Laryngotracheal trauma requires prompt recognition, airway protection, and skillful management to lessen the mortality of this deadly spectrum of injuries.

$\mathrm{L}$ aryngotracheal trauma (LTT) is a rare and life-threatening spectrum of injuries. Schaefer ${ }^{1}$ reported an incidence of 1 in 30,000 emergency visits over a 27-year period for blunt injuries alone. Bent and colleagues ${ }^{2}$ reported an incidence of 1 in 5000 emergency department visits in 1987 for both blunt and penetrating LTT. In a population-based study by Jewett and associates, ${ }^{3}$ an incidence of 1 in 137,000 inpatients was identified. Gussack and coworkers ${ }^{4}$ reported an incidence of less than $1 \%$ of trauma cases. Blunt LTT has a mortality of up to $20 \%$, and penetrating trauma has a mortality rate up to $40 \%$. ${ }^{5,6}$ Successful treatment depends on early diagnosis, complete evaluation of associated injuries, skillful management of the airway, and proper treatment of each injury. ${ }^{7,8}$

Because of the rare occurrences of these injuries, few reports exist that characterize contemporary injury patterns and management techniques. Schaefer ${ }^{1}$ reviewed 139 patients over a 27 -year period in 1992, and Francis and colleagues ${ }^{9}$ 


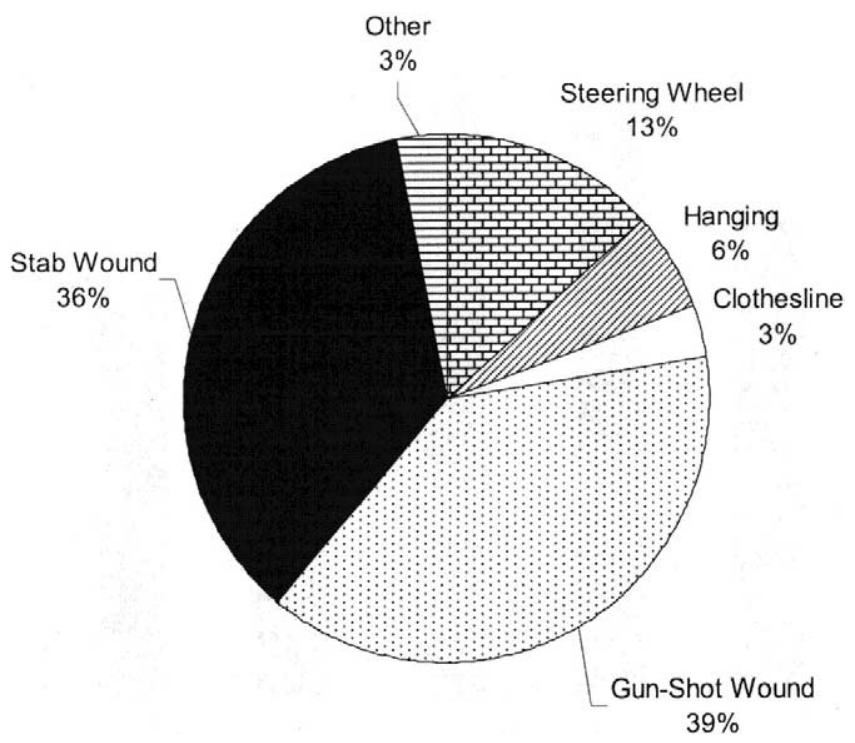

Figure 1. Mechanism of injury for blunt and penetrating LTT.

recently published a report that identified 23 patients over a 6-year period. Our review details contemporary mechanisms, diagnostic modalities, and outcomes of LTT in an urban population.

\section{Patients and Methods}

A total of 44,684 patients with trauma were admitted to 2 level I trauma centers, Parkland Memorial Hospital and Wilford Hall Medical Center, between January 1996 and December 2003. We performed a retrospective analysis of the trauma databases at each hospital within this period to identify all patients with LTT. Isolated injury below the sternal notch excluded patients from the study. We identified and reviewed 71 cases to determine the mechanisms of injury, diagnostic procedures used, associated injuries, and outcomes. There were 56 (78.9\%) male and $15(21.1 \%)$ female patients with a mean age of $32.8 \pm 13.3$ years (range, $15-71$ years). We classified patients into 2 groups on the basis of mechanism, either blunt or penetrating. The blunt group consisted of 19 patients, and the penetrating group contained 52 patients. The follow-up period ranged from 6 months to 8 years. We assessed outcomes in terms of mortality, voice ability, and airway patency. Voice evaluation was scored on individual patients with the following grades: good voice resembled the voice before injury, fair voice differed but was still functional, and poor voice represented aphonia, whisper, or unintelligible speech. ${ }^{2,9,10}$ The airway was graded as good if the patient had a normal airway or if the patient could be decannulated and poor if the patient needed a tracheostomy for airway control. ${ }^{7}$

Categoric variables were analyzed with the $\chi^{2}$ and Fisher exact tests as appropriate in contingency tables, whereas Student $t$ tests and Mann-Whitney $U$ tests were performed as appropriate for comparison of continuous variables. The logistics regression model was applied for univariate and multivariate analyses to confirm the prognostic effect of the factors on mortality. Data were
TABLE 1. Characteristics of patients with laryngotracheal trauma according to trauma type

\begin{tabular}{|c|c|c|c|c|}
\hline Variables & n & $\begin{array}{l}\text { Blunt trauma, } \\
n=19(\%)\end{array}$ & $\begin{array}{c}\text { Penetrating trauma, } \\
n=52(\%)\end{array}$ & $\begin{array}{c}P \\
\text { value }\end{array}$ \\
\hline Age (y) & 71 & $38.5 \pm 15.2$ & $30.1 \pm 11.9$ & .017 \\
\hline \multicolumn{5}{|l|}{ Age (y) } \\
\hline $\begin{array}{l}\text { Less than median } \\
\text { age }(32 \mathrm{y})\end{array}$ & 37 & $5(26.3)$ & $32(61.5)$ & \\
\hline $\begin{array}{l}\text { Great than median } \\
\text { age }(32 \mathrm{y})\end{array}$ & 34 & 14 (73.7) & $20(38.5)$ & .015 \\
\hline \multicolumn{5}{|l|}{ Sex } \\
\hline Male & 56 & $14(73.7)$ & $42(80.8)$ & \\
\hline Female & 15 & $5(26.3)$ & $10(19.2)$ & .525 \\
\hline \multicolumn{5}{|l|}{ Location } \\
\hline Larynx & 15 & $4(21.1)$ & $11(21.2)$ & \\
\hline Trachea & 26 & 2 (10.5) & $24(46.2)$ & \\
\hline Larynx + trachea & 30 & $13(68.4)$ & $17(32.6)$ & $.011^{*}$ \\
\hline \multicolumn{5}{|l|}{ Associated injuries } \\
\hline Head trauma & 6 & $3(30)$ & $3(11.6)$ & \\
\hline Vascular injury & 8 & $3(30)$ & $5(19.2)$ & \\
\hline Esophageal injury & 5 & $1(10)$ & $4(15.4)$ & \\
\hline Chest trauma & 11 & $2(20)$ & $9(34.6)$ & \\
\hline Combined injury & 6 & $1(10)$ & $5(19.2)$ & \\
\hline \multicolumn{5}{|l|}{ Associated injuries } \\
\hline Present & 36 & $10(52.6)$ & $26(50)$ & \\
\hline Absent & 35 & $9(47.4)$ & $26(50)$ & .844 \\
\hline \multicolumn{5}{|l|}{$\begin{array}{c}\text { Emergency airway } \\
\text { requirement }\end{array}$} \\
\hline Present & 39 & $15(78.9)$ & $24(46.2)$ & \\
\hline Absent & 32 & $4(21.1)$ & $28(53.8)$ & .017 \\
\hline \multicolumn{5}{|l|}{ Voice ability } \\
\hline Poor & 2 & $1(14.3)$ & $1(2.2)$ & \\
\hline Fair & 7 & $1(14.3)$ & $6(13.3)$ & \\
\hline Good & 43 & $5(71.4)$ & $38(84.5)$ & $.298 \dagger$ \\
\hline \multicolumn{5}{|l|}{ Airway patency } \\
\hline Poor & 2 & $1(14.3)$ & $1(2.2)$ & \\
\hline Good & 50 & $6(85.7)$ & $44(97.8)$ & .253 \\
\hline \multicolumn{5}{|l|}{ Mortality } \\
\hline Dead & 19 & $12(63.2)$ & 7 (13.5) & \\
\hline Alive & 52 & 7 (36.8) & $45(86.5)$ & $<.0001$ \\
\hline
\end{tabular}

* $P$ value on the basis of injury site (larynx or trachea vs larynx and trachea). $\uparrow P$ value on the basis of voice ability (good vs fair-poor).

expressed as means \pm standard deviation. All statistical analyses were performed with the Statistical Package for Social Sciences (SPSS, version 12.0, Chicago, Ill).

\section{Results}

\section{Blunt Trauma Group}

There were 14 male and 5 female patients in the blunt trauma group with a mean age of $38.5 \pm 15.2$ years (range, 16-69 years). Causative factors included $9(47.4 \%)$ steeringwheel collisions, 4 (21.1\%) hanging injuries, and $2(10.5 \%)$ clothesline mechanisms (Figure 1). In this series $13(68.4 \%)$ cases involved the larynx and the trachea, whereas only 4 


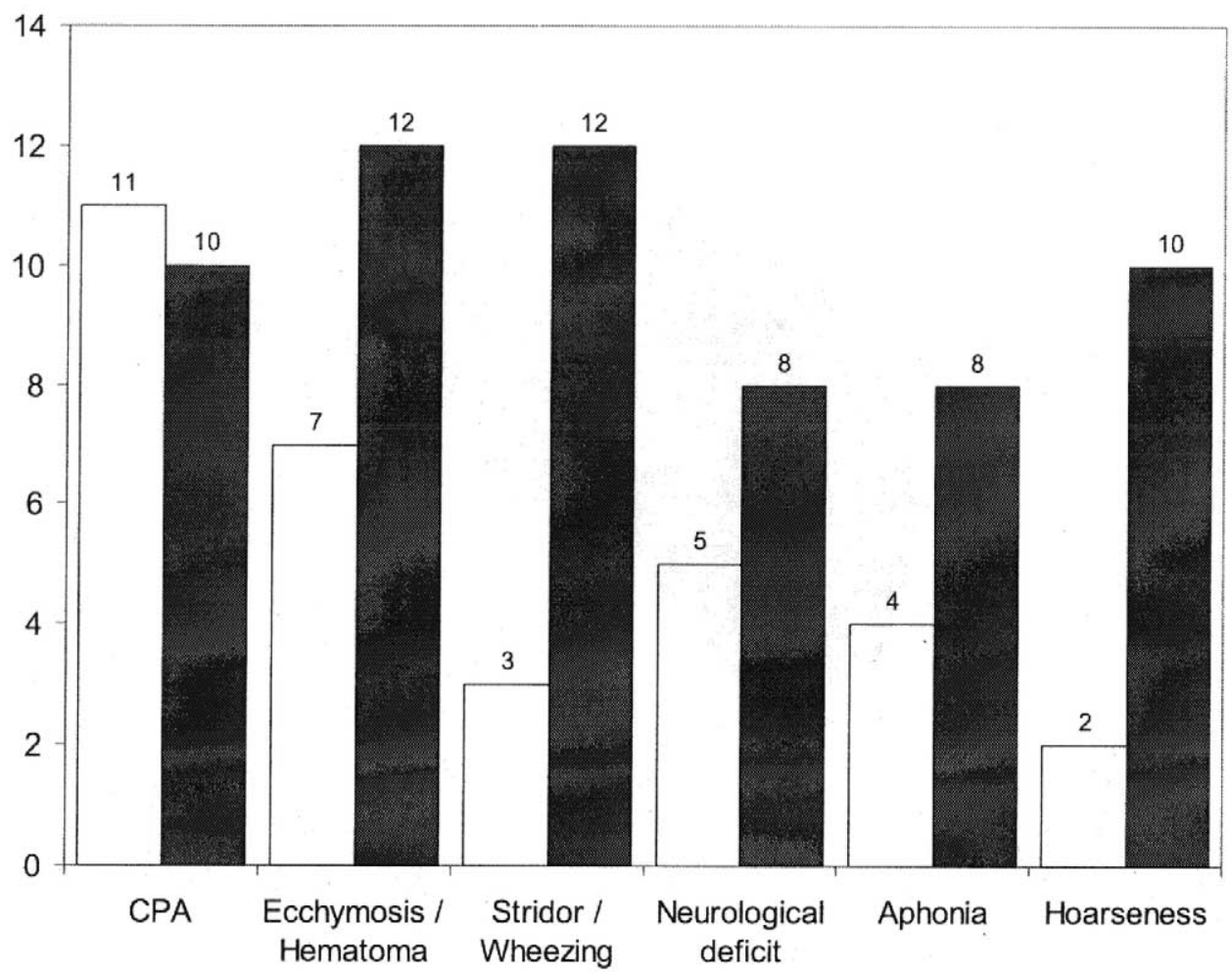

Figure 2. Signs and symptoms of patients with LTT with respect to blunt trauma and penetrating trauma groups. White columns, Blunt ( $=19)$; black columns, penetrating $(\mathrm{n}=52)$.

(21.1\%) patients had isolated laryngeal injury, and 2 $(10.5 \%)$ patients had isolated tracheal injury (Table 1).

Eleven $(57.9 \%)$ of the patients with blunt LTT presented in cardiopulmonary arrest (CPA). Ten of these patients were involved in steering-wheel collisions, and only 1 of these patients was successfully resuscitated. Seven $(36.8 \%)$ patients had cervical ecchymoses, and 5 (26.3\%) patients had neurologic deficits. Apnea occurred in $4(21.1 \%)$ patients, stridor or wheezing occurred in 3 $(15.8 \%)$ patients, and hoarseness occurred in $2(10.5 \%)$ patients (Figure 2).

Fifteen (78.9\%) of the 19 patients required an emergency airway. Fourteen patients were intubated, and 1 required a cricothyroidotomy. One patient who was initially intubated required a subsequent tracheostomy for prolonged airway control. These patients required mechanical ventilation for a mean of $1.2 \pm 1.2$ days (range, 6 hours to 3 days).

Eight $(42.1 \%)$ patients with blunt LTT presented with other injuries. Two patients had cervicothoracic vascular injuries, and 2 others had closed-head injuries (10.5\% each). One $(5.3 \%)$ patient presented with combined vascular and closed-head injuries. Two (10.5\%) patients had nonesophageal thoracic injuries, and 1 (5.3\%) patient had an esophageal injury.
Computed tomography (CT) detected laryngotracheal injuries in $4(21.1 \%)$ patients. Fiberoptic laryngoscopy was diagnostic in the $2(10.5 \%)$ patients who had isolated laryngeal injuries. A combination of both CT scanning and fiberoptic laryngoscopy allowed diagnosis in $2(10.5 \%)$ patients with LTT.

Only 4 of the 19 patients required operative intervention. Two patients required tracheal repair, and a third required laryngeal repair. The fourth patient required an operative tracheostomy. Three other patients were noted to have contusions on diagnostic testing.

Seven (36.8\%) patients survived blunt LTT in this series. Ten $(52.6 \%)$ of the patients presented in CPA and did not respond to Advanced Trauma Life Support/Advanced Cardiac Life Support (ATLS/ACLS) protocols. Two additional patients died within 24 hours of admission of other complications. Good voice quality was present in $5(71.4 \%)$ of the 7 surviving patients, and a good airway was achieved in 6 (85.7\%) patients.

\section{Penetrating Trauma Group}

There were 42 male and 10 female patients in the penetrating trauma group with a mean age of $30.1 \pm 11.9$ years (range, 15-71 years). The most common causative factors 
were gunshot wounds in $26(50.0 \%)$ patients and stab wounds in $24(46.2 \%)$ patients (Figure 1). Two other patients sustained injuries from glass shards when windows shattered. The trachea was the most common site for penetrating mechanisms, with $24(46.2 \%)$ patients sustaining injuries to this location. Seventeen (32.6\%) patients had injuries to both the larynx and the trachea. Only 11 (21.2\%) patients had isolated laryngeal injuries.

The most common findings were $12(23.1 \%)$ patients with cervical ecchymoses or hematomas, $12(23.1 \%)$ patients with stridor or wheezing, $10(19.2 \%)$ patients who presented in CPA, and $9(17.3 \%)$ patients with hemoptysis. Neurologic deficits and aphonia were each present in 8 patients (15.4\% each). Seven (13.5\%) patients had cervical crepitus, and $6(11.5 \%)$ patients had subcutaneous emphysema (Figure 2).

Approximately half of the 52 patients with penetrating injuries required emergency airways through intubation $(n=20)$, tracheostomy $(n=3)$, or cricothyroidotomy $(n=$ 2). Twelve of the patients initially endotracheally intubated or needing cricothyroidotomies required revision to formal tracheostomies in the operating room. An additional 7 patients required operative tracheostomies. Two patients needed emergency cricothyroidotomies in the operating room. One was previously endotracheally intubated, and the other required no initial emergency room airway. Patients with penetrating LTT who necessitated artificial airways required mechanical ventilation for $8.7 \pm 7.6$ days (range, 3 hours to 44 days).

A total of $26(50.0 \%)$ patients had associated injuries. The 2 most common injuries were thoracic trauma in 12 (23.1\%) patients and cervicothoracic vascular injuries in 10 (19.2\%) patients. Five (9.6\%) patients had combinations of closed-head injuries, vascular injuries, esophageal injuries, or nonesophageal thoracic trauma. Both gunshot wounds and stab wounds caused vascular injuries in 5 patients $(9.6 \%$ each). Thoracic trauma was present in $5(9.6 \%)$ patients with gunshot wounds and $7(13.5 \%)$ patients with stab wounds.

Four diagnostic procedures were used in fairly even ratios in patients with penetrating mechanisms. Esophagogastroduodenoscopy, barium swallow, or fiberoptic laryngoscopy was performed in 17 patients, whereas CT scanning was used in 15 patients. Intraoperative esophagoscopy was used in 11 patients for the diagnosis of esophageal perforation.

Forty-four (84.6\%) patients with penetrating LTT underwent operative management of their injuries. Repair of the larynx, trachea, or both occurred in 40 patients. On exploration, the other 4 patients had penetrating neck injuries, with bruising in the laryngotracheal region requiring no formal repair.
TABLE 2. Characteristics of patients with laryngotracheal trauma according to mortality

\begin{tabular}{|c|c|c|c|c|}
\hline Variables & $\mathbf{n}$ & $\begin{array}{c}\text { Dead, } \\
\mathrm{n}=17(\%)\end{array}$ & $\begin{array}{c}\text { Alive, } \\
\mathrm{n}=\mathbf{4 3}(\%)\end{array}$ & $P$ value \\
\hline Age (y) & 71 & $34.4 \pm 14.4$ & $31.6 \pm 12.9$ & .439 \\
\hline \multicolumn{5}{|l|}{ Age (y) } \\
\hline $\begin{array}{l}\text { Less than median } \\
\text { age ( } 32 \mathrm{y})\end{array}$ & 37 & $9(47.4)$ & $28(53.8)$ & \\
\hline $\begin{array}{l}\text { Greater than median } \\
\text { age ( } 32 \mathrm{y})\end{array}$ & 34 & $10(52.6)$ & $24(46.2)$ & .629 \\
\hline \multicolumn{5}{|l|}{ Sex } \\
\hline Male & 56 & 17 (89.5) & $39(75)$ & \\
\hline Female & 15 & 2 (10.5) & $13(25)$ & .324 \\
\hline \multicolumn{5}{|l|}{ Trauma type } \\
\hline Blunt & 19 & $12(63.2)$ & 7 (13.5) & \\
\hline Penetrating & 52 & $7(36.8)$ & $45(86.5)$ & $<.0001$ \\
\hline \multicolumn{5}{|l|}{ Location } \\
\hline Larynx & 15 & $4(21.1)$ & $11(21.2)$ & \\
\hline Trachea & 26 & $3(15.8)$ & $23(44.2)$ & \\
\hline Larynx + trachea & 30 & $12(63.1)$ & $18(34.6)$ & $.056^{*}$ \\
\hline \multicolumn{5}{|l|}{ Associated injuries } \\
\hline Head trauma & 6 & $3(27.3)$ & $3(12)$ & \\
\hline Vascular injury & 8 & $2(18.2)$ & $6(24)$ & \\
\hline Esophageal injury & 5 & $1(9.1)$ & $4(16)$ & \\
\hline Chest trauma & 11 & $2(18.2)$ & $9(36)$ & \\
\hline Combined injury & 6 & $3(27.3)$ & $3(12)$ & \\
\hline \multicolumn{5}{|l|}{ Associated injuries } \\
\hline Present & 36 & $11(57.9)$ & $25(48.1)$ & \\
\hline Absent & 35 & $8(42.1)$ & $27(51.9)$ & .464 \\
\hline \multicolumn{5}{|l|}{$\begin{array}{l}\text { Emergency airway } \\
\text { requirement }\end{array}$} \\
\hline Present & 39 & $18(94.7)$ & $21(40.4)$ & \\
\hline Absent & 32 & $1(5.3)$ & $31(59.6)$ & $<.0001$ \\
\hline
\end{tabular}

*P value on the basis of injury site (larynx or trachea vs larynx and trachea).

There was an $86.5 \%$ survival for patients with penetrating neck injuries. Forty-five patients were followed up for voice and airway quality. Thirty-eight $(84.4 \%)$ patients had good voices, and 44 (97.8\%) patients had good airways.

\section{Comparison of Blunt and Penetrating LTT}

The mean age of patients in the blunt trauma group was $38.5 \pm 15.2$ years, whereas in the penetrating trauma group it was $30.1 \pm 11.9$ years $(P=.017$, Table 1$)$. In addition, trauma location $(P=.011)$, emergency airway requirement $(P=.017)$, and mortality rate $(63.2 \%$ [blunt] vs $13.5 \%$ [penetrating], $P<.0001$ ) differed significantly between the 2 groups (Table 2). Significant univariate predictors of mortality were blunt trauma type $(P=.0001)$, emergency airway requirement $(P=.0021)$, and trauma localization (larynx plus trachea vs either larynx or trachea, $P=.0352$; Table 3). However, multivariate analysis identified only blunt trauma $(P=.0089)$ and need of an emergency airway $(P=.0066)$ as independent predictors of mortality. 
TABLE 3. Univariate and multivariate analysis of 71 patients by a logistic regression model according to mortality

\begin{tabular}{|c|c|c|c|}
\hline Variable & $\begin{array}{c}\text { Relative } \\
\text { risk }\end{array}$ & $\begin{array}{l}95 \% \text { confidence } \\
\text { interval }\end{array}$ & $P$ value \\
\hline \multicolumn{4}{|l|}{ Age (y) } \\
\hline $\begin{array}{l}\text { Greater than median age } \\
\text { vs less than median } \\
\text { age }\end{array}$ & 1.296 & $0.452-3.714$ & .6290 \\
\hline Sex & & & \\
\hline $\begin{array}{l}\text { Male vs female } \\
\text { Trauma type }\end{array}$ & 2.830 & $0.575-13.930$ & .2006 \\
\hline $\begin{array}{l}\text { Blunt vs penetrating } \\
\text { Associated injuries }\end{array}$ & 11.020 & $3.234-37.552$ & .0001 \\
\hline $\begin{array}{l}\text { Present vs absent } \\
\text { Emergency airway } \\
\text { requirement }\end{array}$ & 1.485 & $0.514-4.289$ & .4650 \\
\hline $\begin{array}{l}\text { Present vs absent } \\
\text { Location }\end{array}$ & 26.569 & $3.291-214.469$ & .0021 \\
\hline $\begin{array}{l}\text { Larynx vs trachea } \\
\text { Location }\end{array}$ & 2.787 & $0.529-14.668$ & .2262 \\
\hline $\begin{array}{l}\text { Larynx }+ \text { trachea vs } \\
\text { larynx or trachea }\end{array}$ & 3.237 & $1.085-9.661$ & .0352 \\
\hline Trauma type & & & \\
\hline $\begin{array}{l}\text { Blunt vs penetrating } \\
\text { Emergency airway } \\
\text { requirement }\end{array}$ & 7.554 & $1.661-34.358$ & .0089 \\
\hline $\begin{array}{l}\text { Presence vs absence } \\
\text { Location }\end{array}$ & 20.212 & $2.308-176.970$ & .0066 \\
\hline $\begin{array}{l}\text { Laryngotracheal vs } \\
\text { larynx or trachea }\end{array}$ & 1.425 & $0.328-6.178$ & .6360 \\
\hline
\end{tabular}

\section{Discussion}

LTT is a rare and potentially lethal spectrum of injuries that might be missed without a high index of suspicion. The incidence of LTT in our series is 1 in 15,000 emergency department admissions and represents $0.2 \%$ of all trauma admissions over an 8-year period. Historically, most cases of LTT resulted from blunt-force mechanisms to the cervical region. ${ }^{8,9}$ However, within the last decade, there appears to be a shift in the mechanism of LTT to penetrating injuries (Figure 3). ${ }^{2,3,5,6,8,9,11-16}$ The Federal Bureau of Investigation reports that Dallas, Texas, has the highest crime rate in the nation among cities with populations of greater than 1 million persons, and Dallas also ranks third in the nation in total murder rate. ${ }^{17}$ These facts suggest that penetrating trauma is on the increase in our community. Conversely, decreased rates of blunt LTT might reflect improved automobile safety, lower speed limits, and the mandatory use of safety belts. ${ }^{2}$ In the National Highway Safety Traffic Administration's Traffic Safety Facts: 2002, the number of injuries caused by automobile accidents has steadily decreased over a 7-year period starting in $1995 .{ }^{18}$ This might contribute to the decrease in the incidence of blunt LTT.
Previous reviews of LTT report that the mean age of patients ranges from 26 to 34 years. ${ }^{2,11}$ The mean age within our series is $32.8 \pm 13.3$ years. The average age for patients with a penetrating mechanism is 30 years, which is lower than what Grewal and coworkers ${ }^{19}$ stated in their series. However, the percentage of male and female patients is not different from that seen in previous series. ${ }^{19}$ In this series we demonstrate a significant correlation between the mechanism of trauma (blunt vs penetrating) and age $(P=.017)$; however, age is not a significant factor in mortality $(P=.6290)$.

The most fundamental intervention for patients with laryngotracheal injury is airway control. Either routine intubation or a tracheostomy can secure the airway. A tracheostomy provides space with which to examine the site of injury both at the site and from above with direct laryngoscopy. Endotracheal intubation might render further examination of the injury difficult and might aggravate an existing laryngeal injury. However, there is controversy regarding the best method of gaining a secure airway. Schaefer ${ }^{1}$ avoided intubation in these patients and recommended a tracheostomy using local anesthesia. Similarly, Fuhrman and associates ${ }^{20}$ reported that a tracheostomy should be the only method of airway control used in LTT. In contrast, Gussack and coworkers ${ }^{4}$ argued that endotracheal intubation can safely manage the airway if performed by experienced personnel under direct visualization with a small endotracheal tube. Blind intubation should not be used in patients with potential LTT because of the risk of complete airway obstruction. The Ryder Trauma Center uses specific guidelines for penetrating neck injuries. They suggest using awake fiberoptic intubation, rapid-sequence fiberoptic intubation, rapidsequence induction, or awake orotracheal intubation depending on the emergency need for an airway. If any of these methods fail, a surgical airway through a cricothyroidotomy should be established. ${ }^{21}$ This study demonstrates that emergency endotracheal intubation can be done safely. This can be followed by an operative tracheostomy in patients who require prolonged airway control. In this series 39 (54.9\%) of the 71 patients with LTT required an emergency airway. Fourty-eight percent of patients underwent initial orotracheal intubation, whereas tracheostomy and cricothyroidotomy were performed in $4 \%$ each. Patients with blunt LTT required an emergency airway in $78.9 \%$ of cases, whereas those with penetrating LTT required one in $46.2 \%(P=.017)$. Intubation was successful in 14 of the 15 patients in the blunt trauma group and 20 of the 24 patients in the penetrating trauma group. Moreover, univariate $(P=$ $.0021)$ and multivariate $(P=.0066)$ analyses identified the requirement of an emergency airway as a significant predictor of mortality. 


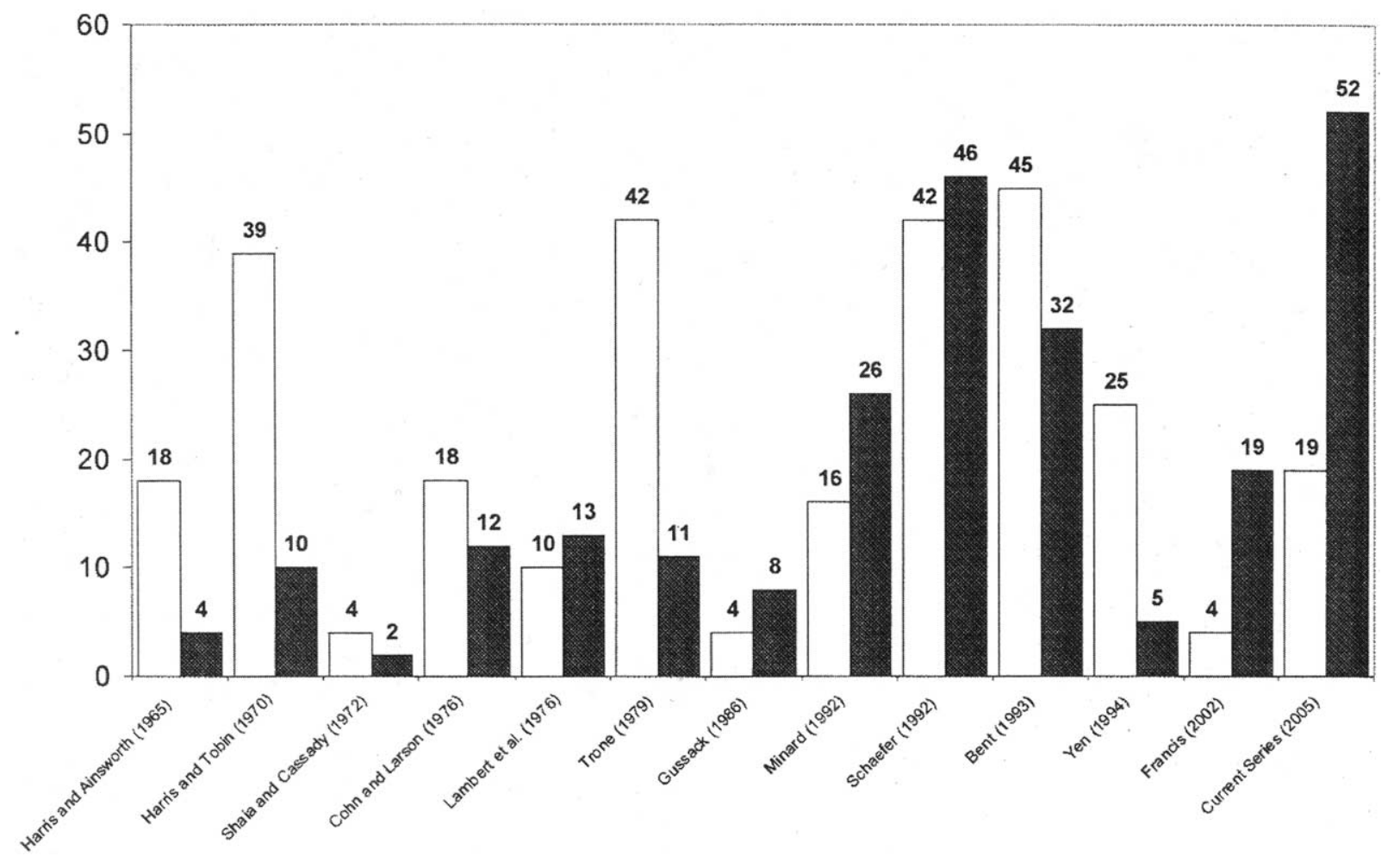

Figure 3. Review of LTT series with respect to blunt trauma and penetrating trauma groups. White columns, Blunt; black columns, penetrating.

There are several diagnostic modalities, in addition to a good physical examination, available for the workup of these patients. Most authors recommend the use of flexible fiberoptic laryngoscopy and CT analysis as excellent adjuvant procedures for the evaluation of laryngotracheal injuries. ${ }^{4,6-8,22}$ Flexible fiberoptic laryngoscopy permits evaluation and often correct assessment of the extent of the laryngeal injury. ${ }^{1}$ Laryngoscopic findings in our study included laceration of the thyroid cartilage, laryngeal tear, laryngeal edema, and hematoma. CT scanning of the neck is useful in patients without hard evidence of LTT. The CT might be helpful in determining the tract of penetrating trauma and identifying those patients who might benefit from further endoscopic or contrast swallow studies. ${ }^{7,22}$ CT findings of LTT included fractures of the cricoid or laryngeal cartilage, subcutaneous hematoma, subcricoid edema, and subcutaneous air surrounding the trachea. CT scanning and flexible fiberoptic laryngoscopy are the 2 most common diagnostic tools in our patients with LTT. Esophagogastroduodenoscopy and barium swallow are 2 additional methods for investigation of the upper aerodigestive tract in patients suspected of having LTT.

The prognosis of laryngotracheal injuries depends primarily on the presence of other major associated injuries.
Injuries with sufficient magnitude to cause severe laryngotracheal damage might also cause injury to the esophagus, cervical spine, and/or vascular structures. In hemodynamically stable patients a detailed examination and appropriate adjuvant diagnostic studies must be pursued. ${ }^{8}$ Esophagoscopy and contrast swallow studies are useful in determining the presence of an esophageal injury. If esophagoscopy cannot rule out esophageal trauma with certainty, contrast swallow might be necessary. ${ }^{2,8,22}$

Bent and colleagues ${ }^{2}$ reported esophageal injuries in $14 \%$ of patients with LTT, closed-head injuries in $28 \%$, and spine trauma in $14 \%$. In the series of Mathisen and Grillo, ${ }^{8}$ thoracic trauma and closed-head injuries were the most common associated injuries. Grewal and associates ${ }^{19}$ reported that the incidence of associated esophageal injuries was $19 \%$ in patients with penetrating LTT. Vascular and esophageal injuries were the most common associated injuries in the series by Gussack and coworkers. ${ }^{4}$ Our results demonstrate that thoracic trauma $(15.5 \%)$ and vascular injuries $(11.3 \%)$ are the most common associated injuries, followed by closed-head trauma $(8.5 \%)$.

Another controversy in the management of LTT is the timing of the operative exploration. Some authors recommend delaying intervention to allow edema to sub- 
side. ${ }^{23,24}$ However, the consensus is that results are better if patients are treated early. Most trauma centers recommend operating within 24 hours if feasible..$^{1,12,25}$ In our series all patients who required operative intervention underwent exploration within 24 hours of admission.

Poor voice quality and poor airway patency were each present in 2 patients in long-term follow-up. This review demonstrates no significant correlation between trauma mechanism and voice quality $(P=.298)$ or airway patency $(P=.253)$. Additionally, we do not find a significant correlation between the presence of an emergency airway and poor voice quality $(P=.181$, data not shown).

LTT remains a rare and life-threatening set of injuries with serious complications. In this series $26.8 \%$ of patients with LTT died (blunt injury [63.2\%] vs penetrating injury [13.5\%]). It is easily overlooked and difficult to diagnose. To improve the dismal outcome of these patients, practitioners must focus on early diagnosis, appropriate management of the airway, identification and treatment of associated trauma, and prompt repair of the injury. Therefore trauma surgeons, thoracic surgeons, otolaryngologists, anesthesiologists, and emergency physicians should be well educated in the management of laryngotracheal injuries.

We thank Tammy Morgan for her support and assistance in cross-referencing the trauma databases to get a concrete set of patients with LTT. We also thank Jesse Williams for his insightful suggestions and review of the manuscript.

\section{References}

1. Schaefer SD. The acute management of external laryngeal trauma. A 27-year experience. Arch Otolaryngol Head Neck Surg. 1992; 118:598-604.

2. Bent JP 3rd, Silver JR, Porubsky ES. Acute laryngeal trauma: a review of 77 patients. Otolaryngol Head Neck Surg. 1993;109:441-9.
3. Jewett BS, Shockley WW, Rutledge R. External laryngeal trauma analysis of 392 patients. Arch Otolaryngol Head Neck Surg. 1999;125: 877-80.

4. Gussack GS, Jurkovich GJ, Luterman A. Laryngotracheal trauma: a protocol approach to a rare injury. Laryngoscope. 1986;96:660-5.

5. Edwards WH Jr, Morris JA Jr, DeLozier JB 3rd, Adkins RB Jr. Airway injuries. The first priority in trauma. Am Surg. 1987;53:192-7.

6. Lambert GE Jr, McMurry GT. Laryngotracheal trauma: recognition and management. JACEP. 1976;5:883-7.

7. Minard G, Kudsk KA, Croce MA, Butts JA, Cicala RS, Fabian TC. Laryngotracheal trauma. Am Surg. 1992;58:181-7.

8. Mathisen DJ, Grillo H. Laryngotracheal trauma. Ann Thorac Surg. 1987;43:254-62.

9. Francis S, Gaspard DJ, Rogers N, Stain SC. Diagnosis and management of laryngotracheal trauma. J Natl Med Assoc. 2002;94:21-4.

10. Cherian TA, Rupa V, Raman R. External laryngeal trauma: analysis of thirty cases. J Laryngol Otol. 1993;107:920-3.

11. Yen PT, Lee HY, Tsai MH, Chan ST, Huang TS. Clinical analysis of external laryngeal trauma. J Laryngol Otol. 1994;108:221-5.

12. Leopold DA. Laryngeal trauma. A historical comparison of treatment methods. Arch Otolaryngol. 1983;109:106-12.

13. Harris HH, Ainsworth JZ. Immediate management of laryngeal and tracheal injuries. Laryngoscope. 1965;75:1103-15.

14. Harris HH, Tobin HA. Acute injuries of the larynx and trachea in 49 patients (observations over a 15-year period). Laryngoscope. 1970;80: 1376-84.

15. Shaia FT, Cassady CL. Laryngeal trauma. Arch Otolaryngol. 1972;95:104-8.

16. Cohn AM, Larson DL. Laryngeal injury: a critical review. Arch Otolaryngol. 1976;102:166-70.

17. Program UCR. Crime in the United States. Washington (DC): Federal Bureau of Investigation; 2004. p. 34.

18. Administration NHST. Traffic safety facts: 2002. Washington (DC): US Department of Transportation; 2002. p. 12.

19. Grewal H, Rao PM, Mukerji S, Ivatury RR. Management of penetrating laryngotracheal injuries. Head Neck. 1995;17:494-502.

20. Fuhrman GM, Stieg FH 3rd, Buerk CA. Blunt laryngeal trauma: classification and management protocol. J Trauma. 1990;30:87-92.

21. Desjardins G, Varon AJ. Airway management for penetrating neck injuries: the Miami experience. Resuscitation. 2001;48:71-5.

22. Vassiliu P, Baker J, Henderson S, Alo K, Velmahos G, Demetriades D. Aerodigestive injuries of the neck. Am Surg. 2001;67:75-9.

23. Pennington CL. External trauma of the larynx and trachea. Immediate treatment and management. Ann Otol Rhinol Laryngol. 1972;81:546-54.

24. Nahum AM. Immediate care of acute blunt laryngeal trauma. J Trauma. 1969;9:112-25.

25. Schaefer SD. The treatment of acute external laryngeal injuries. State of the art. Arch Otolaryngol Head Neck Surg. 1991;117:35-9. 